\title{
Alcohol-Based Hand Sanitizers - A Multidimensional Perspective
}

Nasser N. Nyamweya ${ }^{1, *}$ and Kennedy O. Abuga ${ }^{2}$

1 Pharma Manufacturing Solutions, P.O. Box 21297-00505, Nairobi, Kenya

2 Department of Pharmaceutical Chemistry, School of Pharmacy, College of Health Sciences, University of Nairobi, P.O. Box 19676-00202, Nairobi, Kenya

* To whom correspondence should be addressed.

Email address: nasser04@yahoo.com 


\section{ABSTRACT}

The global use of alcohol based hand sanitizers (ABHS) as a means of controlling the transmission of infectious disease increased dramatically in 2020 as governments and public health agencies across the world advocated hand hygiene as a preventative measure during the COVID-19 pandemic. Although the performance of these products is most commonly defined as a function of their alcohol concentration, they are multifaceted products in which an interplay of several factors is important in determining efficacy. The hand sanitizer tetrahedron, is a novel concept that considers both ABHS formulation factors and product performance factors from a multi-dimensional perspective. The four faces of the tetrahedron represent input/formulation factors: 1) the type and amount of alcohol, 2) inactive ingredients, 3) the type of formulation/delivery system and 4) manufacturing practices. The four corners of the tetrahedron represent output/product performance factors: 1) efficacy, 2) sensory characteristics, 3) usage, usability and compliance and 4) product safety/adverse effects. All factors are of importance to ensuring the effectiveness and utility of these products.

\section{Keywords}

Hand sanitizers, hand rubs, alcohol based, disinfection, hand hygiene, coronavirus, COVID-19 


\section{INTRODUCTION}

Alcohol based hand sanitizers (ABHS) have emerged as an important tool in the fight against SARS-CoV-2, the virus that causes coronavirus disease 2019 (COVID-19) [1]. The disease has spread rapidly throughout the world thereby necessitating stringent measures and controls to minimize its transmission. One of the key measures that has been advocated is the need to ensure hand hygiene. Hand hygiene is also a factor in the transmission of several other infectious diseases [2].

Hand sanitizers are products that are applied and rubbed over the surface of the hands to inactivate pathogenic microorganisms. These products are designed to dry rapidly after application thereby eliminating the need for soap, water and drying aids such as towels. The convenience and portability of hand sanitizers has led to their widespread availability with usage sharply increasing in 2020 when ABHS were recommended by the World Health Organization $(\mathrm{WHO})$ as an alternative hand hygiene measure [3].

Ethanol or isopropanol (2-propanol) are the commonly alcohols used in ABHS. They are typically formulated as aqueous mixtures with several other ingredients such as emollients, moisturizers and fragrances. Although the focus of most concern regarding ABHS performance has been the alcohol concentration, added ingredients and auxiliary factors also play a role in the efficacy, safety and long-term utility of these products.

In this paper, the factors influencing the attributes of ABHS are illustrated in the novel concept of the hand sanitizer tetrahedron (Figure 1). In this model, each of the faces of the tetrahedron represents inputs in the manufacturing of the product, i.e., 1) the type and amount of alcohol, 2) inactive ingredients, 3) the formulation, and 4) manufacturing practices. The four corners of the tetrahedron represent the product performance factors: 1) efficacy, 2) sensory characteristics, 3) usage and compliance, and 4) product safety. While these factors are often considered individually, the long-term use of ABHS requires that manufacturers of these products address 
the manner in which the factors relate to each other and are integrated to provide a quality product.

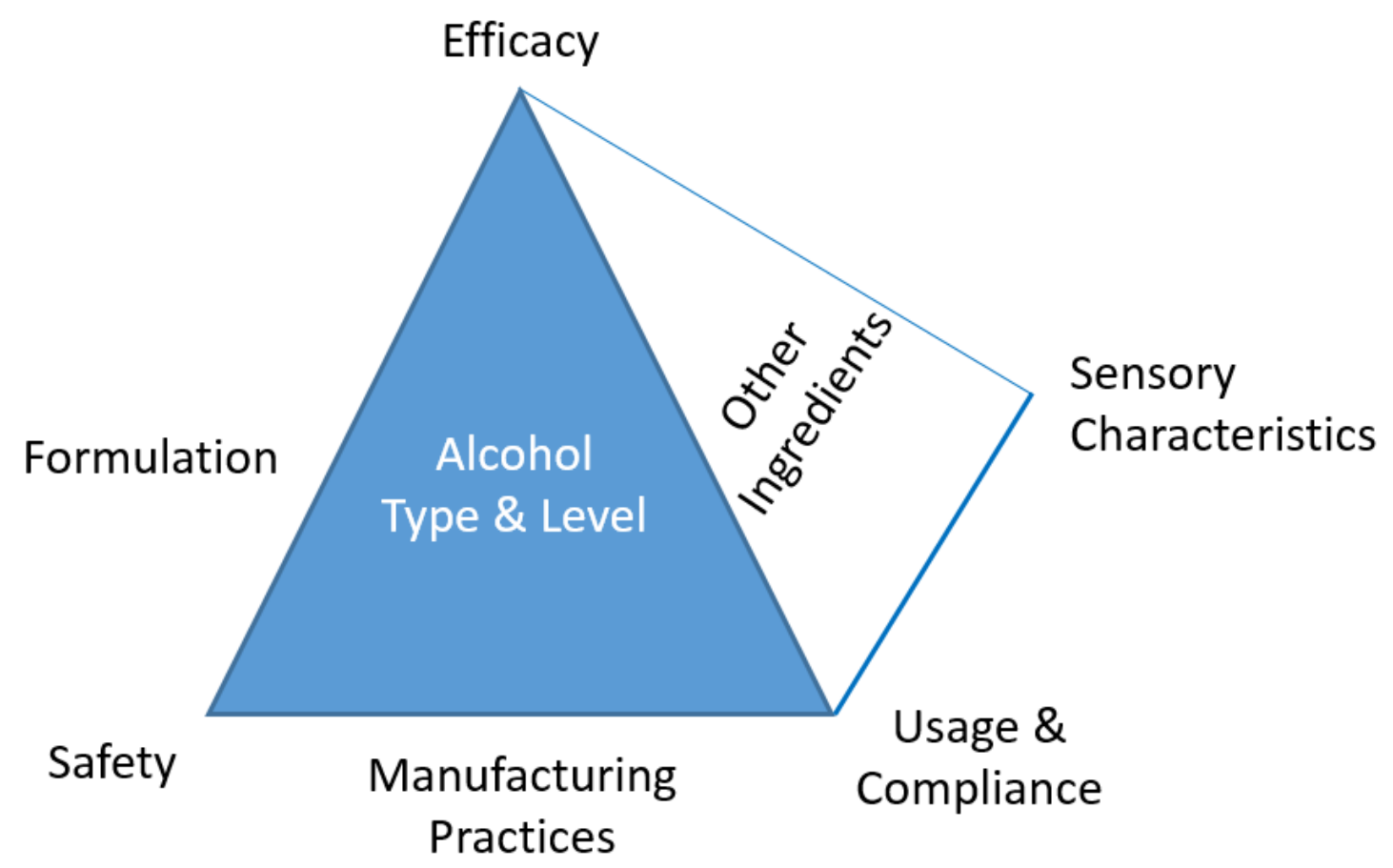

Figure 1. The ABHS tetrahedron of manufacturing inputs and performance factors.

\section{THE FACES OF THE TETRAHEDRON: INPUTS}

The principal ingredients in ABHS are an alcohol (or mixture of alcohols) and water. Additionally, ABHS may have other ingredients which perform a variety of functions (Table 1). The key considerations for ABHS manufacturers are the influence of these ingredients on product efficacy, safety and usage. The WHO has developed two formulations based on either ethanol $(80 \% \mathrm{v} / \mathrm{v})$ or isopropanol $(75 \% \mathrm{v} / \mathrm{v})$ with glycerol $(1.45 \% \mathrm{v} / \mathrm{v})$ and hydrogen peroxide $(0.125 \% \mathrm{v} / \mathrm{v})[4]$. Both formulations have broad spectrum antimicrobial activity including efficacy against SARS-CoV-2. Firms which manufacture commercial $\mathrm{ABHS}$ on a regular basis typically use proprietary formulations. 
Table 1. Ingredients commonly used in commercial ABHS products

\begin{tabular}{|c|c|c|}
\hline Ingredient & Functions & Examples ${ }^{1}$ \\
\hline Active (alcohol) & Inactivate susceptible microorganisms & $\begin{array}{l}\text { Ethanol, isopropanol, } \\
\text { n-propanol }{ }^{2}\end{array}$ \\
\hline Solvent/Cosolvent & $\begin{array}{l}\text { - Facilitate alcohol protein denaturation } \\
\text { - Reduce product volatility }\end{array}$ & Water \\
\hline Humectant & Facilitate skin hydration & Glycerol, Propylene glycol \\
\hline Emollient & $\begin{array}{l}\text { Maintain skin softness, smoothness, } \\
\text { pliability }\end{array}$ & $\begin{array}{l}\text { Caprylyl glycol, Isopropyl } \\
\text { myristate }\end{array}$ \\
\hline Thickener & Increase viscosity; reduce spillage/runoff & $\begin{array}{l}\text { Carbomer, Acrylates/C10- } \\
30 \text { alkyl acrylate } \\
\text { crosspolymer }\end{array}$ \\
\hline $\begin{array}{l}\mathrm{pH} \\
\text { agent }\end{array}$ & $\begin{array}{l}\text { Neutralization of acrylic acid based } \\
\text { polymers to enhance viscosity }\end{array}$ & $\begin{array}{l}\text { Aminomethyl propanol, } \\
\text { Triethanolamine }\end{array}$ \\
\hline Fragrance & $\begin{array}{l}\text { Enhance aesthetic appeal; ameliorate/mask } \\
\text { alcohol odor }\end{array}$ & Linalool, Limonene \\
\hline $\begin{array}{l}\text { Other } \\
\text { - Antioxidant } \\
\text { - Multifunctional }\end{array}$ & $\begin{array}{l}\text { Ameliorate adverse effects of alcohols on } \\
\text { the skin }\end{array}$ & $\begin{array}{l}\text { - Tocopheryl acetate } \\
\text { - Aloe vera }\end{array}$ \\
\hline
\end{tabular}

${ }^{1}$ some ingredients may have more than one or overlapping functions

${ }^{2} \mathrm{n}$-propanol is not approved for use in the US

\subsection{Alcohol Type and Level}

The active ingredient in ABHS is aqueous alcohol in optimized concentrations. Alcohols are known to possess broad-spectrum antimicrobial activity against bacteria, fungi and viruses. While the specific mechanism of action of alcohols is not clear, it is thought to be related to denaturation of membrane and enzymatic proteins [5].

Three alcohol homologs are utilized in ABHS namely, ethanol, isopropanol and n-propanol. The US Food and Drug Administration (FDA), however, does not approve the use of n-propanol in ABHS [6].

Methanol is toxic and too polar to exert the desired biocidal activity. Consequently, there are specific warnings against its use as a component in ABHS. Despite this, ABHS containing 
methanol have been encountered in the market [7]. Higher alcohol homologs do not possess favorable properties (e.g., polarity, volatility, organoleptic characteristics and industrial sources) for use in ABHS.

From the foregoing, the two most widely used alcohols in ABHS formulations are ethanol and isopropanol. Isopropanol is more effective against bacteria while ethanol is favorably virucidal, which may be due to differences in polarity [5]. Amongst the usable alcohols, ethanol emerges as the most common choice since it is easily produced through fermentation and distillation. For the formulation of $\mathrm{ABHS}$, pharmaceutical or food grade ethanol is recommended. Use of technical grade alcohol is typically not permitted due the high level of impurities. Nevertheless, due to the high demand for ABHS during the COVID-19 pandemic, special authorization to use these products may be granted provided the raw materials meet the acceptance criteria that would justify application. The FDA guidance specifies control of alcohol impurities such as benzene, methanol, acetaldehyde and acetal to levels below specified limits. Non-compliance to these limits necessitates further testing for specific residual solvents in accordance to $\mathrm{ICH}-\mathrm{Q} 3 \mathrm{C}$ guidelines [6].

The efficacy of alcohol as antiseptic is highly dependent on its concentration. The recommended alcohol concentration in ABHS is generally cited a $60-95 \%(v / v)$. However, the optimum level is nuanced and is not necessarily the same for ethanol and isopropanol. This recommended alcohol ranges permit the alcohol to interact with functional proteins hence exert activity. The lower range $(60-75 \%)$ readily denatures proteins while higher levels (>95\%) cause coagulation of membrane proteins thus preventing the alcohol from entering the cell. Moreover, alcohol levels of above $80 \%$ may reduce the contact time due to volatility which undermines efficacy of the formulation [8].

It may be desirable to prefer a median alcohol concentration of $70-80 \%(\mathrm{v} / \mathrm{v})$. Products formulated with alcohol levels close to the $60 \%$ lower limit risk the active ingredient content falling below the threshold during processing, transport, storage or use as constituent alcohols may 
evaporate. Post market surveillance reports by regulatory authorities in a number of countries have found some products with alcohol assays below threshold limits $[9,10]$.

\subsection{Other Ingredients}

Key considerations with regards to the use of ingredients are their influence on ABHS efficacy, safety and usage. The most commonly added ingredients in commercial ABHS formulations are humectants, thickeners and fragrances. Humectants such as glycerol help counteract the drying effect of alcohols, which may otherwise adversely affect skin integrity, especially with frequent and long term ABHS use. Thickeners, are added to increase viscosity and facilitate application of ABHS by making them easier to handle and reducing spillage. They are most often polymers of acrylic acid and its derivatives such as carbomers [8].

The other commonly observed ingredients in commercial ABHS products are aloe and tocopherols, which in addition to possible beneficial dermatological effects, may enhance marketing appeal. Denaturing agents, such as denatonium benzoate, sucrose octaacetate, isopropanol or triethyl citrate are added to deter ingestion of ABHS [6].

Ingredient effects in ABHS formulations may be complex sometimes resulting in unintended outcomes. An interesting example is glycerol, the most frequently used humectant. Although structurally a sugar alcohol with reported antimicrobial activity of its own at high concentrations [11], a number of studies have reported that glycerol can reduce the antimicrobial activity of ABHS $[12,13,14,15]$. In the latter study which used the ethanol-based WHO formulation, lowering the glycerol level to $0.5 \%(\mathrm{v} / \mathrm{v})$ was recommended as an optimal balance between antimicrobial efficacy and dermal tolerability. The reason for glycerol's effects on antimicrobial efficacy has not been elucidated, but may be related to its viscosity (which decreases the diffusion of the germicidal alcohol) when used above determinate levels. Since over-drying of the hands can be detrimental to skin integrity, the most commonly suggested solution has been to use a lower level of glycerol (as opposed to eliminating it completely). 
Certain ingredients can potentiate antimicrobial ABHS activity. Organic acids, such as citric acid and phosphoric acid have been reported to increase the activity of ABHS against non-enveloped viruses $[16,17,18,19]$.

Non-alcohol based hand sanitizers contain other antimicrobial agents such as benzalkonium chloride (BKC) [20]. Unlike alcohols, these ingredients are not volatile and hence antimicrobial activity can persist for longer periods [21]. Chlorhexidine is an example of an antimicrobial agent which has been combined with alcohol in some ABHS products [22,23] although its additional benefit has been questioned $[24,25]$. The use of such combinations is uncommon and may be restricted to ABHS employed in health care settings in some countries.

An area which has not been extensively studied with ABHS is the potential for interactions between the various formulation ingredients. One reported example is that of chlorhexidine, which is cationic, with carbomer (an anionic polymer). Inactivation of chlorhexidine activity was observed in the presence of a carbomer containing ABHS [26]. There is also a potential for chlorhexidine to interact with anionic emulsifiers [27].

Additional potential interactions may arise from the presence of hydrogen peroxide, a strong oxidizing agent. Hydrogen peroxide $\left(\mathrm{H}_{2} \mathrm{O}_{2}\right)$, is a component of the two WHO recommended formulations [4]. The function of hydrogen peroxide is to inactivate bacterial spores that may be present as alcohols lack sporicidal action.

In good manufacturing practice (GMP) manufacturing environments, with more stringent control of raw materials, facilities and equipment, the use of $\mathrm{H}_{2} \mathrm{O}_{2}$ in the formulation is atypical. In cases where $\mathrm{H}_{2} \mathrm{O}_{2}$ is used, any ingredients that are susceptible to oxidation should not be included. Interactions between $\mathrm{H}_{2} \mathrm{O}_{2}$ and gel-forming polyacrylic acid polymers leading to a reduction in liquid viscosity have been reported [28]. In the study, polymer cross-link density, peroxide levels and the source/grade of $\mathrm{H}_{2} \mathrm{O}_{2}$ were shown to influence changes in viscosity. 
The potential for ingredient-ingredient interactions and ingredient-container interactions will increase with the number of raw materials used in the formulation. Therefore, manufacturers should carefully consider the necessity of each added ingredient to the formulation.

\subsection{Formulation}

A number of delivery systems can be used for ABHS including liquids, gels, sprays, foams and wipes (Table 2). In hospitals and other public facilities, hand sanitizers are commonly packaged in dispensers.

Table 2. ABHS Delivery Formats

\begin{tabular}{|c|c|c|c|}
\hline Format & Delivery mode & Advantages & Disadvantages \\
\hline $\begin{array}{l}\text { Liquid (low } \\
\text { viscosity } \\
\text { solutions) }\end{array}$ & $\begin{array}{l}\text { - Pouring/squeezing } \\
\text { from bottles } \\
\text { - Pumping from } \\
\text { containers } \\
\text { - Dispensers }\end{array}$ & $\begin{array}{l}\text { - Portable } \\
\text { - Widely available }\end{array}$ & $\begin{array}{l}\text { - Spillage, dose metering } \\
\text { - Alcohol odor may be more } \\
\text { pronounced }\end{array}$ \\
\hline Gel & $\begin{array}{l}\text { - Pouring/squeezing } \\
\text { from bottles } \\
\text { - Pumping from } \\
\text { containers } \\
\text { - Dispensers }\end{array}$ & $\begin{array}{l}\text { - As for liquids, but } \\
\text { with better dose } \\
\text { metering, handling } \\
\text { characteristics }\end{array}$ & $\begin{array}{l}\text { - Spillage, antimicrobial } \\
\text { action may not be as rapid } \\
\text { as that of liquids } \\
\text { - Longer drying time than } \\
\text { liquids }\end{array}$ \\
\hline Foams & $\begin{array}{l}\text { - Dispensers } \\
\text { - Special containers }\end{array}$ & $\begin{array}{l}\text { - As for gels, but with } \\
\text { reduced spillage } \\
\text { - May be preferred by } \\
\text { some consumers }\end{array}$ & $\begin{array}{l}\text { - More expensive than liquids } \\
\text { or gels }\end{array}$ \\
\hline Dispensers & $\begin{array}{l}\text { - Mechanical (lever) } \\
\text { - Touchless (sensor) }\end{array}$ & $\begin{array}{l}\text { - Controlled dose } \\
\text { metering for liquids, } \\
\text { gels and foams }\end{array}$ & $\begin{array}{l}\text { - Device malfunctioning will } \\
\text { prevent dosing } \\
\text { - Potential fomite risks } \\
{[80,81]}\end{array}$ \\
\hline Sprays & - Actuation of a valve & $\begin{array}{l}\text { - Controlled dose } \\
\text { metering }\end{array}$ & $\begin{array}{l}\text { - Product losses to } \\
\text { atmosphere } \\
\text { - Potential for inhalation } \\
\text { - Higher flammability risk if } \\
\text { incorrectly used }\end{array}$ \\
\hline Wipes & $\begin{array}{l}\text { - ABHS is transferred } \\
\text { from wipe to surface of } \\
\text { the skin }\end{array}$ & $\begin{array}{l}\text { - Dose metering } \\
\text { - Portable, } \\
\text { convenient, no } \\
\text { spillage }\end{array}$ & $\begin{array}{l}\text { - Needs to be designed to } \\
\text { provide sufficient amount of } \\
\text { ABHS in each wipe } \\
\text { - Non-biodegradable fabrics }\end{array}$ \\
\hline
\end{tabular}


Low viscosity liquids and gels are the most common delivery modes for ABHS sold to the general public. Gels are essentially liquids with a significantly higher viscosity which assists in their application, especially from smaller containers. Liquids are better suited to delivery systems which have a higher degree of metering capability (e.g., dispensers, sprays and containers equipped with pump fittings). Gels, along with foams, are preferred by many users due to greater ease of handling compared to low viscosity liquids [29]. Some studies, however, have suggested that the higher viscosity of gels may lower antimicrobial activity, possibly due to reduced diffusivity of the alcohol $[30,31]$. However, it appears that formulation factors such as increasing the concentration of alcohol may in such cases be used to improve efficacy [30].

The very different nature of other delivery formats makes comparisons challenging. Wipes or towelettes are a format that may be preferred by some people as they avoid the possibility of spillage that is associated with liquids or gels. A number of studies have compared different delivery systems. In one study, gel, foam and wipe ABHS delivery systems were comparable (no significant differences) in reduction of virus counts on the hands [32]. Another study comparing single packet packaged $A B H S$ and wipes revealed that patients preferred the packaged $A B H S$ to the wipe as they found it easier to handle [33].

\subsection{Manufacturing and Packaging}

In order to ensure that ABHS of suitable quality are produced, GMPs should be followed in their production. This includes the use of suitable manufacturing facilities, equipment, raw materials, systems, procedures, quality control testing, storage and distribution along with the requisite documentation and records.

Many countries have specific regulations that govern the production of ABHS [34]. In Europe, ABHS are regulated under the Biocidal Products Regulation $[8,35]$. In the United States, ABHS are regulated as a drug products by the FDA. Furthermore, the FDA distinguishes between health care antiseptics and consumer antiseptic products [36]. 
Raw materials should meet the established standards for the countries in which the ABHS will be marketed. For example, in the US, ethanol, isopropanol and glycerol should meet United States Pharmacopoeia (USP) or Food Chemicals Codex (FCC) specifications [6].

The safety of personnel involved in manufacturing and packaging operations is critical, especially given the potential of organic solvents to be flammable and explosive under uncontrolled conditions. Proper storage of alcohols and the use of air-conditioned and well-ventilated manufacturing rooms is necessary. Equipment grounding, the use of pneumatic mixers to prevent static discharge, lowering oxygen levels in mixing vessels and keeping alcohol vapor levels in the manufacturing rooms below threshold limits are examples of production safety measures that can be implemented [37].

While packaging may be sometimes considered secondary to the formulation of the ABHS, it is a critical component in ensuring product integrity, stability and delivery. ABHS are most commonly packaged in plastic containers. Container corrosion has been observed for the ethanol-based WHO formulation when packaged in aluminum beer cans [38].

Dispensers are commonly used for ABHS delivery in hospitals and other settings with high numbers of people. The design and function of dispensers are important in ensuring their effectiveness. In a study at a hospital which had recently installed dispensers, malfunctioning was a common occurrence [39]. The need for regular auditing and maintenance of dispenser units has been stressed [40].

\section{THE CORNERS OF THE TETRAHEDRON: OUTPUTS}

\subsection{ABHS Efficacy}

The efficacy of an ABHS is its key performance attribute. Depending on the application, target microorganisms and delivery mode, there are various standard test methods used to determine product efficacy [41]. Efficacy testing is generally performed using tests that measure the number 
of microorganisms before and after treatment with ABHS. Test results are typically expressed in terms of log10 reduction factors. The key factors influencing ABHS efficacy are the level and the type of alcohol used. However, added ingredients can also have significant influence on efficacy. For example, recent studies have shown that while the current $\mathrm{WHO}$ formulations do not meet the requirements for EN 1500 (hygienic hand rub) or EN 12791 (surgical hand preparation), using higher alcohol levels (i.e., $80 \%$ ethanol or $75 \%$ isopropanol on a weight instead of the current volume basis) and lowering the glycerol level to $0.5 \%(\mathrm{v} / \mathrm{v})$ enables these modified formulations to meet both EN test criteria [42].

\subsection{Sensory Characteristics}

The sensory characteristics of ABHS include the appearance, odor, viscosity, texture, skin feel, stickiness and residual feel of the product. Although sensory properties may not directly influence the efficacy of the product, they do play an important role in determining aesthetic appeal, which in turn determines the likelihood of individuals using a given product. Therefore, improving compliance may help reduce the transmission of infectious disease. Alcohols have a distinct sharp odor which many users may find unpleasant. The use of fragrances mitigates the intensity of the alcohol odor and also serves to distinguish various products therefore making it an important manufacturing consideration.

Viscosity is a key property of ABHS as it influences factors such as dispensing, pourability, spreadability onto the skin and stickiness. Viscosity also influences drying time, which is an important consideration in user compliance.

The importance of sensory factors on compliance of ABHS has been studied [29]. Key desirable properties that were identified in the study included rapid absorption, a moisturizing hand feel, the absence of stickiness, a clean feel, and the absence of or minimal odor. Gels have been reported to have better organoleptic properties than liquid formulations [31]. 


\subsection{Use and Compliance}

Proper product use is a critical component of the ABHS tetrahedron because even the best product will not be efficacious if used improperly. Key criteria in proper use of ABHS are the amount of product applied, the application time, the use of the proper technique and the drying time. Furthermore, application and drying times contribute to user acceptability and compliance $[43,44,45,46]$. The benefits of instruction on ABHS use have been demonstrated with one study showing that training of health care workers on the proper technique resulted in improvements in both compliance and the effectiveness of hand sanitization [47].

Inadequate directions for use have been observed in many consumer ABHS products [48]. It is somewhat puzzling that manufacturers would invest time and resources into designing an efficacious product, yet to pay little attention to the importance of providing adequate directions for how the users will apply the product. The need to view the product holistically is emphasized in the perspective of the tetrahedron. Improper or insufficient application of ABHS will negate the ability of the product to properly disinfect the hands. Additionally, the importance of readability and font size should be considered. This is especially a concern for small, portable ABHS bottle sizes.

ABHS users should be directed to apply amounts that are sufficient to wet the entire surface of the hands. Ideally, if the appropriate amounts of an efficacious ABHS are used, the applied product should dry rapidly so that the user can resume other activities. Long drying times, stickiness and residual effects are undesirable and may adversely influence compliance.

\subsection{Safety}

The main safety concerns with finished ABHS products at the consumer level are their flammability, ingestion (accidental or intentional) and dermatological effects [49]. 


\subsubsection{Flammability}

Alcohols are flammable organic solvents. This is attributable to their intrinsic chemical ability to spontaneously undergo combustion in exothermic reactions that generate energy in the form of heat and light. Alcohols are volatile with flashpoints that can elicit combustion below room temperature. The flashpoint is dependent on the vapor pressure of a liquid (or liquid mixture) since it is the vapor which supports combustion (Table 3 ). The flashpoint increases with increasing amounts of water, since water is not flammable. Ethanol-water mixtures at the operational concentrations in $\mathrm{ABHS}$ are flammable with flashpoints in the range of $17.5-22^{\circ} \mathrm{C}[50,51]$.

The flammability risk poses fire hazards to ABHS users if these products are incorrectly used or stored. The ABHS may catch fire in the containers, during application or once applied onto users' hands thus causing thermal injuries. A case of an individual who suffered burns from exposing hands wet with sanitizer to a flame illustrates this potential risk [52]. It is therefore necessary to provide appropriate warnings concerning flammability on product labels. For this purpose, specific cautions with respect with location of dispensers, storage areas and use are essential.

\subsubsection{ABHS Ingestion (accidental and intentional)}

ABHS, especially in liquid or gel packaged containers present ingestion risks [53]. ABHS products adulterated with methanol are especially concerning due to its higher toxicity. The intentional misuse of $A B H S$ as a substitute for ethanolic beverages has led to serious adverse health consequences and deaths [54]. ABHS products may also be accidentally ingested by children [55]. In the US between 2011 and 2014 more than sixty-five thousand unintentional ABHS exposures in children less than or equal to 12 years were reported, the majority of which were by ingestion [56].

Recently, the FDA has found methanol in several marketed ABHS products in the US [57]. In one of these products the concentration of methanol was $81 \%$ [58]. This highlights the importance of. 
Table 3. Selected thermodynamic properties of the main ABHS components

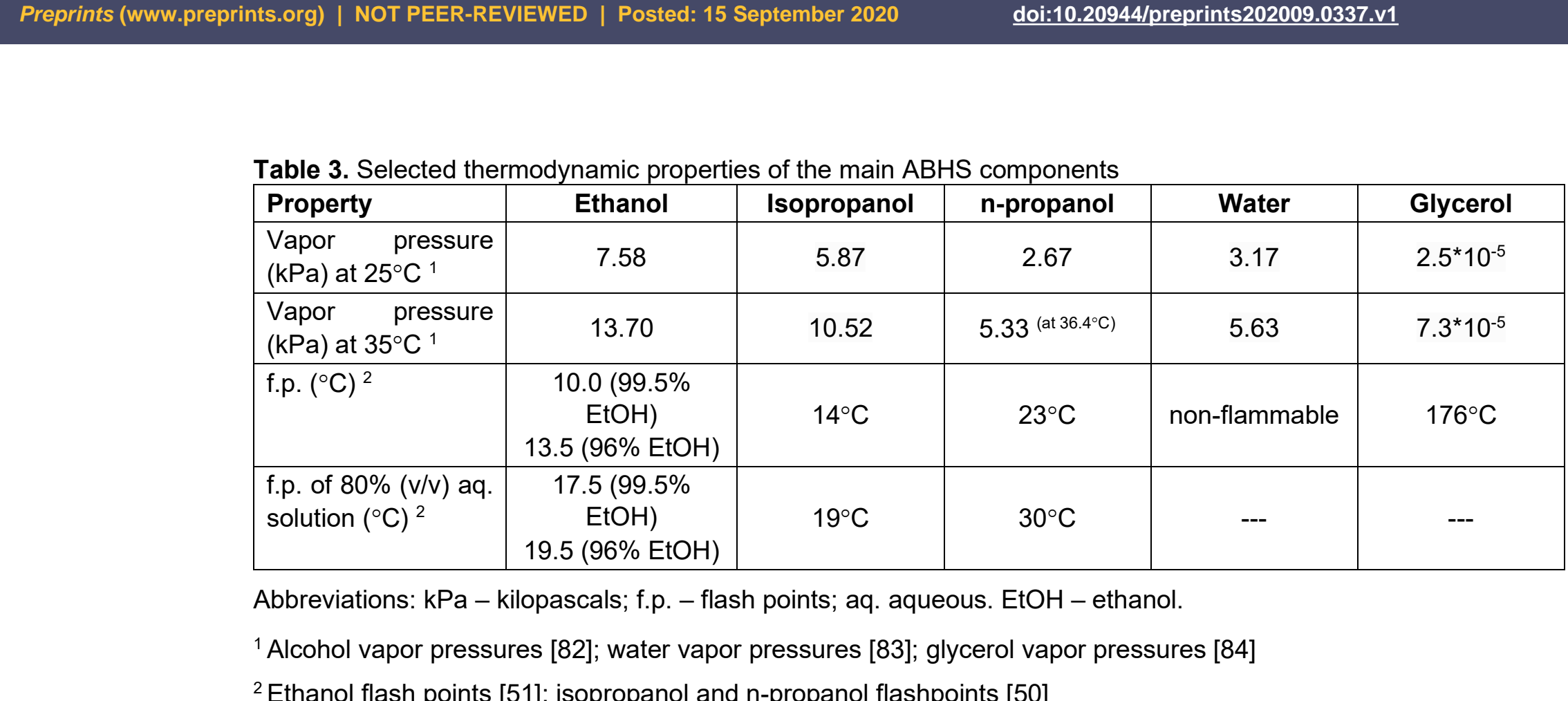

Abbreviations: $\mathrm{kPa}$ - kilopascals; f.p. - flash points; aq. aqueous. EtOH - ethanol.

${ }^{1}$ Alcohol vapor pressures [82]; water vapor pressures [83]; glycerol vapor pressures [84]

${ }^{2}$ Ethanol flash points [51]; isopropanol and $\mathrm{n}$-propanol flashpoints [50]

Ela

(1)

.

(1)

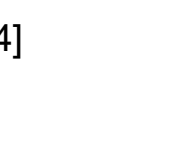


manufacturers ensuring that they have adequate quality controls to prevent adulterated products from reaching the market In some cases, methanol is used as an ethanol substitute by ABHS manufacturers if it is more readily available or less costly than the permitted alcohols. Tragically, such actions resulted in hundreds of deaths and numerous cases of loss of sight in Iran in 2020 when individuals unknowingly consumed ABHS tainted with methanol [59].

The need by ABHS manufacturers to avoid methanol and methylated spirits containing methanol is critical [60]. Notably, the addition of denaturing agents to ABHS is a critical aspect of reducing the risk of their oral ingestion. Furthermore, stringent regulatory oversight is required to monitor ABHS manufacturers and supply chains [9].

\subsubsection{Skin Integrity (dryness, irritation and contact dermatitis potential)}

The tolerability of ABHS is listed as one of the six golden rules of hand hygiene [61]. Even though, the dermal tolerability of an ABHS does not affect efficacy, adverse skin effects will most likely have a negative effect on usage and compliance. Frequent application of skin irritants and allergens can result in contact dermatitis [62]. Generally, ABHS have been considered to have a low incidence of adverse dermal effects except for, in some cases, drying of the skin $\left[63^{\prime} 64,65\right]$. Application of moisturizing creams if $\mathrm{ABHS}$ are frequently used has been suggested [66]. Alcohols show a low potential for contact dermatitis although they may cause a burning sensation if they are applied to irritated or damaged skin $[67,68]$.

Recently, a specific case was reported in which a 12 year-old child developed contact irritant dermatitis following the over-application of a $70 \%$ isopropanol-based hand sanitizer [69]. Ethanol has been reported to be capable of causing contact dermatitis, although the causative chemical may be not necessarily be the alcohol but associated impurities or an aldehyde metabolite [70]. The potential of isopropanol to cause contact dermatitis has also been reported [71], with a possible mechanism being suggested as aldehyde dehydrogenase deficiency leading to the accumulation of acetaldehyde [72]. 
The incorporation of an emollient combination (myristyl alcohol, glycerol, dexpanthenol, levomenol and lanolin alcohol) was reported to reduce contact dermatitis in a controlled, randomized, double-blind trial [73].

Tocopherol, fragrances, propylene glycol, benzoates, and cetyl stearyl alcohol have been reported as common potential allergens in ABHS used in the United States [74]. Fragrances in particular are a frequent cause of contact allergies in personal care products [75]. While some fragrance compounds may themselves be weak sensitizers, the oxidation of parent compounds may result in the generation of potent allergens [76].

Increased frequency of hand eczema resulting from increased hand hygiene measures have been reported $[77,78,79]$, although these reports did not indicate whether this was due to increased hand washing or ABHS use.

\section{DISCUSSION}

The proposed hand sanitizer tetrahedron captures the relationships between ABHS product inputs and outputs. For example, the previously mentioned approaches that have been used by a number of researchers to improve the efficacy of the WHO formulations reveal an interplay between alcohol level and added ingredients (e.g., glycerol) that influences product efficacy. The counteracting influence of humectants on the drying effects of alcohols show how potential adverse effects on the integrity of the skin by ABHS can be mitigated. ABHS delivery formats are a contributing factor to the use of ABHS by individuals who may exhibit preferences for a specific type of product. Delivery systems and sensory characteristics of ABHS play an important role in making these products more attractive to users which is a critical component of compliance. While, it may be argued that sensory characteristics do not play a role in efficacy, it is quite clear from the widespread use of fragrances and coloring agents in commercially marketed ABHS products that they do influence customer appeal which indirectly relate to usage and compliance. 
The majority of ABHS studies have been performed in hospital environments or controlled settings. The challenge though now in the COVID-19 environment is that ABHS are being widely used by the general public in a multitude of products and delivery formats. With the tremendous increase in ABHS use globally product factors such as ease of use, convenience, portability, user preferences, how well users follow directions for use and safety will become increasingly important. The evaluation of the quality attributes of ABHS products will therefore need to encompass a range of factors that are illustrated in the ABHS tetrahedron.

\section{CONCLUSIONS}

It is anticipated that the ABHS tetrahedron will be a useful conceptual model for manufacturers of ABHS and related products. It provides an illustrative yet comprehensive view of the interplay of factors that are important in the efficacy, safety and use of ABHS. 


\section{REFERENCES}

1. Pradhan D, Biswasroy $P$, Kumar Naik P, Ghosh G, Rath G. A review of current interventions for covid-19 prevention. Arch Med Res. 2020;51(5):363-374. doi:10.1016/j.arcmed.2020.04.020.

2. Boyce JM, Pittet D. Healthcare Infection Control Practices Advisory Committee. Society for Healthcare Epidemiology of America. Association for Professionals in Infection Control. Infectious Diseases Society of America. Hand Hygiene Task Force, 2002. Guideline for Hand Hygiene in Health-Care Settings: recommendations of the Healthcare Infection Control Practices Advisory Committee and the HICPAC/SHEA/APIC/IDSA Hand Hygiene Task Force. Infect Control Hosp Epidemiol. 2002;23(12 Suppl). doi:10.1086/503164.

3. W.H.O. Coronavirus disease (COVID-19) advice for the public. Published 2020. Accessed September 12, 2020. https://www.who.int/emergencies/diseases/novel-coronavirus2019/advice-for-public.

4. W.H.O. Guide to local production: WHO-recommended handrub formulations. Published online 2010. Accessed September 12, 2020.

https://www.who.int/gpsc/5may/Guide_to_Local_Production.pdf?ua=1.

5. McDonnell G, Russell AD. Antiseptics and disinfectants: activity, action, and resistance. Clin Microbiol Rev. 1999;12(1):147-179. doi:10.1128/CMR.12.1.147.

6. F.D.A. Temporary Policy for Preparation of Certain Alcohol-Based Hand Sanitizer Products During the Public Health Emergency (COVID-19) Guidance for Industry. Published online 2020. Accessed September 12, 2020. https://www.fda.gov/drugs/coronavirus-covid-19drugs/hand-sanitizers-covid-19.

7. Chan A, Chan T. Methanol as an unlisted ingredient in supposedly alcohol-based hand rub can pose serious health risk. Int J Environ Res Public Health. 2018;15(7):1440. doi:10.3390/ijerph15071440.

8. Berardi A, Perinelli DR, Merchant HA, et al. Hand sanitisers amid CoViD-19: A critical review of alcohol-based products on the market and formulation approaches to respond to increasing demand. Int J Pharm. 2020;584:119431. doi:10.1016/j.ijpharm.2020.119431.

9. Jairoun AA, Al-Hemyari SS, Shahwan M. The pandemic of COVID-19 and its implications for the purity and authenticity of alcohol-based hand sanitizers: The health risks associated with falsified sanitizers and recommendations for regulatory and public health bodies. Res Social Admin Pharm. 2020;S1551-7411(20)30393-4. doi:10.1016/j.sapharm.2020.04.014.

10. Fonseca Jr. FS, Brito LR e, Pimentel MF, Leal LB. Determination of Ethanol in Gel Hand Sanitizers Using Mid and Near Infrared Spectroscopy. Journal of the Brazilian Chemical Society. 2020;31:1759-1763.

11. Nalawade TM, Bhat K, Sogi SH. Bactericidal activity of propylene glycol, glycerine, polyethylene glycol 400, and polyethylene glycol 1000 against selected microorganisms. $J$ Int Soc Prev Community Dent. 2015;5(2):114-119. doi:10.4103/2231-0762.155736. 
12. Suchomel M, Kundi M, Pittet D, Rotter ML. Modified World Health Organization hand rub formulations comply with European efficacy requirements for preoperative surgical hand preparations. Infect Control Hosp Epidemiol. 2013;34(3):245-250. doi:10.1086/669528.

13. Suchomel M, Rotter M, Weinlich M, Kundi M. Glycerol significantly decreases the three hour efficacy of alcohol-based surgical hand rubs. J Hosp Infect. 2013;83(4):284-287. doi:10.1016/j.jhin.2012.11.030.

14. Thaddeus NI, Francis EC, Jane OO, Obumneme AC, Okechukwu EC. Effects of some common additives on the antimicrobial activities of alcohol-based hand sanitizers. Asian Pac J Trop Med. 2018;11:222-226. doi:10.4103/1995-7645.228437.

15. Menegueti MG, Laus AM, Ciol MA, et al. Glycerol content within the WHO ethanol-based handrub formulation: balancing tolerability with antimicrobial efficacy. Antimicrob Resist Infect Control. 2019;8:109. doi:10.1186/s13756-019-0553-z.

16. Macinga DR, Sattar SA, Jaykus LA, Arbogast JW. Improved inactivation of nonenveloped enteric viruses and their surrogates by a novel alcohol-based hand sanitizer. Appl Environ Microbiol. 2008;74(16):5047-5052. doi:10.1128/AEM.00487-08.

17. Turner RB, Fuls JL, Rodgers ND. Effectiveness of hand sanitizers with and without organic acids for removal of rhinovirus from hands. Antimicrob Agents Chemother. 2010;54(3):1363-1364. doi:10.1128/AAC.01498-09.

18. Ionidis G, Hübscher J, Jack T, et al. Development and virucidal activity of a novel alcoholbased hand disinfectant supplemented with urea and citric acid. BMC Infect Dis. 2016;16:77. doi:10.1186/s12879-016-1410-9.

19. Kampf G. Efficacy of ethanol against viruses in hand disinfection. $J$ Hosp Infect. 2018;98(4):331-338. doi:10.1016/j.jhin.2017.08.025.

20. Golin AP, Choi D, Ghahary A. Hand sanitizers: A review of ingredients, mechanisms of action, modes of delivery, and efficacy against coronaviruses. Am J Infect Control. 2020;48(9):1062-1067. doi:10.1016/j.ajic.2020.06.182.

21. Bondurant SW, Duley CM, Harbell JW. Demonstrating the persistent antibacterial efficacy of a hand sanitizer containing benzalkonium chloride on human skin at 1, 2, and 4 hours after application. Am J Infect Control. 2019;47(8):928-932. doi:10.1016/j.ajic.2019.01.004.

22. Olson LK, Morse DJ, Duley C, Savell BK. Prospective, randomized in vivo comparison of a dual-active waterless antiseptic versus two alcohol-only waterless antiseptics for surgical hand antisepsis. Am J Infect Control. 2012;40(2):155-159. doi:10.1016/j.ajic.2011.10.012.

23. Deshpande A, Fox J, Wong KK, et al. Comparative Antimicrobial Efficacy of Two Hand Sanitizers in Intensive Care Units Common Areas: A Randomized, Controlled Trial. Infect Control Hosp Epidemiol. 2018;39(3):267-271. doi:10.1017/ice.2017.293.

24. Macinga DR, Edmonds SL, Campbell E, McCormack RR. Comparative efficacy of alcoholbased surgical scrubs: the importance of formulation. AORN J. 2014;100(6):641-650. doi:10.1016/j.aorn.2014.03.013. 
25. Hennig TJ, Werner S, Naujox K, Arndt A. Chlorhexidine is not an essential component in alcohol-based surgical hand preparation: a comparative study of two handrubs based on a modified EN 12791 test protocol. Antimicrob Resist Infect Control. 2017;6:96. doi:10.1186/s13756-017-0258-0.

26. Kaiser N, Klein D, Karanja P, Greten Z, Newman J. Inactivation of chlorhexidine gluconate on skin by incompatible alcohol hand sanitizing gels. Am J Infect Control. 2009;37(7):569573. doi:10.1016/j.ajic.2008.12.008.

27. Jing J, Pei Yi T, Bose R, McCarthy JR, Tharmalingam N, Madheswaran T. Hand sanitizers: a review on formulation aspects, adverse effects, and regulations. Int J Environ Res Public Health. 2020;17(9):3326. doi:10.3390/ijerph17093326.

28. Lubrizol. Stability of Pharmaceutical Carbopol Polymer Gels Containing Hydrogen Peroxide.; 2007. Accessed September 12, 2020. https://www.lubrizol.com//media/Lubrizol/Life-Sciences/Documents/TDS/TDS361_Stability_Pharm_Carbopol_Gels_Containing_Hydrogen_Peroxide.pdf.

29. Greenaway RE, Ormandy K, Fellows C, Hollowood T. Impact of hand sanitizer format (gel/foam/liquid) and dose amount on its sensory properties and acceptability for improving hand hygiene compliance. J Hosp Infect. 2018;100(2):195-201.

30. Kramer A, Rudolph P, Kampf G, Pittet D. Limited efficacy of alcohol-based hand gels. Lancet. 2002;359(9316):1489-1490. doi:10.1016/S0140-6736(02)08426-X.

31. Ochwoto M, Muita L, Talaam K, et al. Anti-bacterial efficacy of alcoholic hand rubs in the Kenyan market, 2015. Antimicrob Resist Infect Control. 2017;6:17. doi:10.1186/s13756017-0174-3.

32. Larson EL, Cohen B, Baxter KA. Analysis of alcohol-based hand sanitizer delivery systems: efficacy of foam, gel, and wipes against influenza $\mathrm{A}(\mathrm{H} 1 \mathrm{~N} 1)$ virus on hands. Am J Infect Control. 2012;40(9):806-809. doi:10.1016/j.ajic.2011.10.016.

33. Rai H, Knighton S, Zabarsky TF, Donskey CJ. Comparison of ethanol hand sanitizer versus moist towelette packets for mealtime patient hand hygiene. Am J Infect Control. 2017;45(9):1033-1034. doi:10.1016/j.ajic.2017.03.018.

34. Dicken RD, Gallagher T, Perks S. Overcoming the Regulatory Hurdles for the Production of Hand Sanitizer for Public Health Protection: The UK and US Academic Perspective. $J$ Chem Saf. 2020;27(4):209-213. doi:10.1021/acs.chas.0c00065.

35. ECHA. Information on biocides. Published online 2020. Accessed September 12, 2020. https://echa.europa.eu/information-on-chemicals/biocidal-products.

36. F.D.A. Topical antiseptic products: hand sanitizers and antibacterial soaps. Published 2020. Accessed September 12, 2020. https://www.fda.gov/drugs/information-drugclass/topical-antiseptic-products-hand-sanitizers-and-antibacterial-soaps

37. Thomson EL, Bullied AR. Production of ethanol-based hand sanitizer in breweries during the COVID-19 crisis. Tech Q Master Brew Assoc Am. 2020;57:47-52. doi:10.1094/TQ-571-0417-01. 
38. Thomson EL, Bullied AR. Corrosion resistance of aluminum beer cans containing hand sanitizer. J Am Soc Brew Chem. Published online 2020.

doi:10.1080/03610470.2020.1784634

39. Kohan C, Ligi C, Dumigan DG, Boyce JM. The importance of evaluating product dispensers when selecting alcohol-based handrubs. Am J Infect Control. 2002;30(6):373375. doi:10.1067/mic.2002.125586.

40. Bánsághi $\mathrm{S}$, Soule H, Guitart $\mathrm{C}$, Pittet $\mathrm{D}$, Haidegger T. Critical Reliability Issues of Common Type Alcohol-Based Handrub Dispensers. Antimicrob Resist Infect Control. 2020;9(1):90. doi:10.1186/s13756-020-00735-4.

41. Rotter M, Sattar S, Dharan S, Allegranzi B, Mathai E, Pittet D. Methods to evaluate the microbicidal activities of hand-rub and hand-wash agents. J Hosp Infect. 2009;73(3):191199. doi:10.1016/j.jhin.2009.06.024.

42. Suchomel M, Eggers M, Maier S, Kramer A, Dancer SJ, Pittet D. Evaluation of World Health Organization-recommended hand hygiene formulations. Emerg Infect Dis. 2020;26(9):10 32012609 201761. doi:10.3201/eid2609.201761.

43. Voss A, Widmer AF. No time for handwashing $[28$ Handwashing versus alcoholic rub: can we afford 100\% compliance? Infect Control Hosp Epidemiol. 1997;18(3):205-208. doi:10.1086/647590.

44. Wilkinson M, Ormandy K, Bradley CR, Fraise AP, Hines J. Dose considerations for alcohol-based hand rubs. J Hosp Infect. 2017;95(2):175-182.

doi:10.1016/j.jhin.2016.12.023.

45. Kramer A, Pittet D, Klasinc R, et al. Shortening the application time of alcohol-based hand rubs to 15 seconds may improve the frequency of hand antisepsis actions in a neonatal intensive care unit. Infect Control Hosp Epidemiol. 2017;38(12):1430-1434. doi:10.1017/ice.2017.217.

46. Harnoss JC, Dancer SJ, Kaden CF, et al. Hand antisepsis without decreasing efficacy by shortening the rub-in time of alcohol-based handrubs to 15 seconds. J Hosp Infect. 2020;104(4):419-424. doi:10.1016/j.jhin.2019.09.004.

47. Widmer AF, Conzelmann M, Tomic M, Frei R, Stranden AM. Introducing alcohol-based hand rub for hand hygiene: the critical need for training. Infect Control Hosp Epidemiol. 2007;28(1):50-54. doi:10.1086/510788.

48. Nyamweya NN, Abuga KO. A Survey of Alcohol-Based Hand Sanitizers in Nairobi: Packaging, Labelling and Regulatory Compliance. East Cent Afr J Pharm Sci. 2020;23(2):72-76.

49. Atolani O, Baker MT, Adeyemi OS, et al. COVID-19: Critical discussion on the applications and implications of chemicals in sanitizers and disinfectants. EXCLI J. 2020;19:785-799. doi:10.17179/excli2020-1386.

50. Astbury GR, Bugand-Bugandet J, Grollet ES, K.M. Flash points of aqueous solutions of flammable solvents. Inst Chem Eng Symp Ser. 2004;(150). 
51. Janès $A, J$. C, J. Experimental determination of flash points of flammable liquid aqueous solutions. Chem Eng Trans. 2013;31:943-948. doi:10.3303/CET1331158.

52. O'Leary FM, Price GJ. Alcohol hand gel-a potential fire hazard. J Plast Reconstr Aesthet Surg. 2011;64(1):131-132. doi:10.1016/j.bjps.2010.03.026.

53. Gormley NJ, Bronstein AC, Rasimas JJ, et al. The rising incidence of intentional ingestion of ethanol-containing hand sanitizers. Crit Care Med. 2012;40(1):290-294.

doi:10.1097/CCM.0b013e31822f09c0.

54. Yip L, Bixler D, Brooks DE, et al. Serious Adverse Health Events, Including Death, Associated with Ingesting Alcohol-Based Hand Sanitizers Containing Methanol - Arizona and New Mexico, May-June 2020. MMWR Morb Mortal Wkly Rep. 2020;69(32):10701073. doi:10.15585/mmwr.mm6932e1.

55. Mahmood A, Eqan M, Pervez S, et al. COVID-19 and frequent use of hand sanitizers; human health and environmental hazards by exposure pathways. Sci Total Environ. 2020;742:140561. doi:10.1016/j.scitotenv.2020.140561.

56. Santos C, Kieszak S, Wang A, Law R, Schier J, Wolkin A. Reported adverse health effects in children from ingestion of alcohol-based hand sanitizers - United States, 2011-2014. MMWR Morb Mortal Wkly Rep. 2017;66(8):223-226. doi:10.15585/mmwr.mm6608a5.

57. F.D.A. FDA updates on hand sanitizers consumers should not use https://www.fda.gov/drugs/drug-safety-and-availability/fda-updates-hand-sanitizersconsumers-should-not-use.

58. F.D.A. FDA advises consumers not to use hand sanitizer products manufactured by Eskbiochem. Published 2020. Accessed September 12, 2020. https://www.fda.gov/drugs/drug-safety-and-availability/fda-advises-consumers-not-usehand-sanitizer-products-manufactured-eskbiochem.

59. Delirrad M, Mohammadi AB. New methanol poisoning outbreaks in Iran following covid-19 pandemic. Alcohol Alcohol. 2020;55(4):347-348. doi:10.1093/alcalc/agaa036.

60. Dear K, Grayson L, Nixon R. Potential methanol toxicity and the importance of using a standardised alcohol-based hand rub formulation in the era of COVID-19. Antimicrob Resist Infect Control. 2020;9(1):129. doi:10.1186/s13756-020-00788-5.

61. Kampf G. The six golden rules to improve compliance in hand hygiene. J Hosp Infect. 2004;56 Suppl 2:3- 5. doi:10.1016/j.jhin.2003.12.023.

62. Jakasa I, Thyssen JP, Kezic S. The role of skin barrier in occupational contact dermatitis. Exp Dermatol. 2018;27(8):909-914. doi:10.1111/exd.13704.

63. Widmer AF. Replace Hand Washing with Use of a Waterless Alcohol Hand Rub? Clinical Infectious Diseases. 2000;31(1):136-143. doi:10.1086/313888

64. Graham M, Nixon R, Burrell LJ, Bolger C, Johnson PD, Grayson ML. Low rates of cutaneous adverse reactions to alcohol-based hand hygiene solution during prolonged use 
in a large teaching hospital. Antimicrob Agents Chemother. 2005;49(10):4404-4405. doi:10.1128/AAC.49.10.4404-4405.2005.

65. Larson E, Girard R, Pessoa-Silva CL, Boyce J, Donaldson L, Pittet D. Skin reactions related to hand hygiene and selection of hand hygiene products. Am J Infect Control. 2006;34(10):627-635. doi:10.1016/j.ajic.2006.05.289.

66. Rundle CW, Presley CL, Militello M, et al. Hand hygiene during COVID-19.

Recommendations from the American Contact Dermatitis Society J Am Acad Dermatol. 2020;S0190-9622(20)32256-8. doi:10.1016/j.jaad.2020.07.057.

67. Kampf G, Löffler H. Prevention of irritant contact dermatitis among health care workers by using evidence-based hand hygiene practices: a review. Ind Health. 2007;45(5):645-652. doi:10.2486/indhealth.45.645.

68. Löffler H, Kampf G. Hand disinfection: how irritant are alcohols? J Hosp Infect. 2008;70 Suppl 1:44-48. doi:10.1016/S0195-6701(08)60010-9.

69. Inder D, Kumar P. Isopropyl alcohol (70\%)-based hand sanitizer-induced contact dermatitis: A case report amid Covid-19. Indian J Case Rep. 2020;6(6):403-405. doi:10.32677/IJCR.2020.v06.i07.017.

70. Ophaswongse $\mathrm{S}$, Maibach $\mathrm{HI}$. Alcohol dermatitis: allergic contact dermatitis and contact urticaria syndrome. A review. Contact Derm. 1994;30(1):1-6. doi:10.1111/j.16000536.1994.tb00719.x.

71. García-Gavín J, Lissens R, Timmermans A, Goossens A. Allergic contact dermatitis caused by isopropyl alcohol: a missed allergen? Contact Derm. 2011;65(2):101-106. doi:10.1111/j.1600-0536.2011.01936.x.

72. Löffler H, Kampf G, Lachenmeier D, Diepgen TL, John SM. Allergic or irritant contact dermatitis after patch testing with alcohol-that is the point. Contact Derm. 2012;67(6):386388. doi:10.1111/cod.12003.

73. Kampf G, Wigger-Alberti W, Schoder V, Wilhelm KP. Emollients in a propanol-based hand rub can significantly decrease irritant contact dermatitis. Contact Derm. 2005;53(6):344349. doi:10.1111/j.0105-1873.2005.00727.x.

74. Voller LM, Schlarbaum JP, Hylwa SA. Allergenic Ingredients in Health Care Hand Sanitizers in the United States. Dermatitis. Published online 2020. doi:10.1097/DER.0000000000000567.

75. Johansen JD. Fragrance contact allergy: a clinical review. Am J Clin Dermatol. 2003;4(11):789-798. doi:10.2165/00128071-200304110-00006

76. Bråred Christensson J, Hagvall L, Karlberg A-T. Fragrance Allergens, Overview with a Focus on Recent Developments and Understanding of Abiotic and Biotic Activation. Cosmetics. 2016;3:19.

77. Guertler A, Moellhoff N, Schenck TL, et al. Onset of occupational hand eczema among healthcare workers during the SARS-CoV-2 pandemic: Comparing a single surgical site 
with a COVID-19 intensive care unit. Contact Derm. 2020;83(2):108-114.

doi:10.1111/cod.13618.

78. Giacalone S, Bortoluzzi P, Nazzaro G. The fear of COVID-19 infection is the main cause of the new diagnoses of hand eczema: Report from the frontline in Milan. Dermatologic Therapy. 2020;33(4):e13630. doi:10.1111/dth.13630

79. Singh M, Pawar M, Bothra A, Choudhary N. Overzealous hand hygiene during the COVID 19 pandemic causing an increased incidence of hand eczema among general population. $J$ Am Acad Dermatol. 2020;83(1):e37-e41. doi:doi:10.1016/j.jaad.2020.04.047

80. Eiref SD, Leitman IM, Riley W. Hand sanitizer dispensers and associated hospital-acquired infections: friend or fomite? Surg. Infect (Larchmt. 2012;13(3):137-140.

doi:10.1089/sur.2011.049.

81. Hongsoongnern P, Britton A, Shah V, Kachur R, Nicksic J, Handley A. Reduced germ exposure from changing out manual soap and sanitizer dispensers to touchless closed system dispensers. Am J Infect Control. 2016;44(6). doi:10.1016/j.ajic.2016.04.084.

82. Mackay D, Shiu WY, Ma K-C, Lee SC. Handbook of Physical-Chemical Properties and Environmental Fate for Organic Chemicals. second. CRC Press; 2006.

83. Lide DR. CRC Handbook of Chemistry and Physics. eighty-fifth. CRC Press; 2004.

84. Cammenga HK, Schulze FW, Theuerl W. Vapor pressure and evaporation coefficient of glycerol. J Chem Eng Data. 1977;22(2):131-134. doi:10.1021/je60073a004. 